\title{
Insignificant effects of culm age on transpiration in a managed Moso bamboo forest, Kyoto, Japan
}

\author{
Kenji Tsuruta $^{1}$, Motonori Okumura ${ }^{1 *}$, Tomonori Kume ${ }^{2}$, \\ Ryuji Ichihashi ${ }^{3}$, Yoshinori Shinohara ${ }^{4}$ and Yoshiko Kosugi ${ }^{1}$ \\ ${ }^{I}$ Graduate School of Agriculture, Kyoto University, Japan \\ ${ }^{2}$ School of Forestry and Resource Conservation, National Taiwan University, Taiwan \\ ${ }^{3}$ Faculty of Agriculture, Kagawa University, Japan \\ ${ }^{4}$ Faculty of Agriculture, Kyushu University, Japan
}

\begin{abstract}
:
The expansion of Moso bamboo forests in Japan might change transpiration and therefore reduce the availability of water resources. Moso bamboo stands are often composed of culms with various ages and older culms may have lower sap flux density $\left(F_{\mathrm{d}}\right)$, which may in turn affect individual culm transpiration $\left(Q_{\mathrm{t}}\right)$, probably because vascular bundles do not regenerate after sprouting. Information related to the differences of $F_{\mathrm{d}}$ and $Q_{\mathrm{t}}$ between younger and older culms would be important for (i) understanding the effects of culm age structure changes on stand-scale transpiration $\left(E_{\mathrm{C}}\right)$, and (ii) developing sampling strategies for $E_{\mathrm{C}}$ estimates in Moso bamboo forests. We conducted sap flux measurements for 15 individuals from four culm age classes in a managed Moso bamboo forest in Kameoka, Kyoto, Japan. Differences in $F_{\mathrm{d}}$ were not significant among the four culm age classes with almost the same stem diameter at breast height (DBH). $Q_{\mathrm{t}}$ was related to DBH across four age classes, indicating that culm age had no apparent effect on $Q_{\mathrm{t}}$ in the forest. Our results suggest the effects of culm age structure changes on $E_{\mathrm{C}}$ are small, and contribute to development of sampling strategy without considering culm age structure for $E_{\mathrm{C}}$ estimates at this site.
\end{abstract}

KEYWORDS age structure; Moso bamboo; sap flux; water use

\section{INTRODUCTION}

More than 70 genera of Bamboo occur naturally in tropical, subtropical and temperate regions around the world, from sea level to $4000 \mathrm{~m}$ a.s.l. although they are naturally absent in Europe (e.g., Gratani et al., 2008). Moso bamboo (Phyllostachys pubescens) is a useful plant in terms of providing food and materials for humans, and is often planted and cultivated. However, a decline of the bamboo industry has caused many Moso bamboo plantations to be abandoned. Left unmanaged, the fast-growing Moso bamboo forests have been expanding and are replacing surrounding vegetation such as coniferous plantation forests and natural broadleaved forests in eastern Asia, such as in Japan (e.g., Shinohara et al., 2014), Taiwan (e.g., Chiou et al., 2009) and mainland China (Song et al., 2011).

Transpiration is one of the major components of the forest water cycle, and therefore affects water yield (e.g., Oishi et al., 2010). Characterizing transpiration of bamboo species is necessary to allow an assessment of the potential effects of the expansion of bamboo species on local water cycles. The sap flux measurement technique is a useful method for investigating stand-scale transpiration especially in mountainous areas with a mosaic of vegetation coverage, because this technique is not limited by complex terrain and spatial heterogeneity (e.g., Wilson et al., 2001). Several studies have examined transpiration in bamboo forests based on sap flux measurements (Dierick et al., 2010; Kume et al., 2010b; Komatsu et al., 2010). Previous studies quantified standscale transpiration in Moso bamboo forests in Fukuoka, Japan, indicating greater stand-scale transpiration occurs in Moso bamboo forests when compared with surrounding coniferous forests (Komatsu et al., 2010; Ichihashi et al., 2015). The larger amounts of transpiration observed in the Moso bamboo forests ( $\sim 100-300 \mathrm{~mm} \mathrm{yr}^{-1}$ larger when compared with surrounding forests) may be attributable to larger canopy conductance in Moso bamboo forest compared to other forest types (Komatsu et al., 2012), the strong ability of this species to transport water from the roots to the leaves (Imaji et al., 2013) and the ability of the species to generate high root pressure (Wang et al., 2011; Cao et al., 2012).

Although previous studies have characterized stand-scale transpiration for Moso bamboo, currently no studies have considered the potential effects of culm age structure of a stand (relative composition of older and younger culms) on stand-scale transpiration in Moso bamboo forests.

Firstly, Moso bamboo tends to show a 2-year cycle of new shoot production; a year with new shoots is described as an on-year and a following off-year production cycle (Li et al., 1998). The newly emerged shoots reach the canopy (typically $>10 \mathrm{~m}$ ) within 1 or 2 months (Isagi et al., 1997). In a bamboo stand in China, about one-third of the bamboo culms in a stand were replaced by new culms every 2 years (Li et al., 1998). Thus, inter-annual variations in age structure are significant in bamboo stands. Unlike tree species, established bamboo culms do not show stem diameter growth and renewal of xylem vessels or tracheids after their initial establishment. The aging of a culm without the renewal of vascular bundles might be associated with 
decreasing functionality of the hydraulic transport system caused by cavitation. This could lead to a decrease in leaf stomatal conductance and/or leaf area (e.g., Sperry, 1993; Meinzer et al., 1995; Dierick et al., 2010) and, hence, result in a decrease in the individual culm transpiration rate in older culms. Thus, to understand the potential effects of culm age structure changes on stand-scale transpiration, we need to clarify sap flux and individual culm transpiration in response to the aging of culms.

Secondly, stand transpiration estimates based on sap flux normally use a limited number of samples in a stand. For single species plantations, samples are generally selected based on tree size (i.e., Diameter at Breast Height; DBH), because $\mathrm{DBH}$ is a major determinant of the transpiration of trees, and biased sampling with regard to tree sizes could cause a significant error in estimating stand-scale transpiration (Čermák et al., 1995; Kume et al., 2010a). In the case of bamboo, if aging results in decreased individual culm transpiration caused by a dysfunction of the hydraulic system, samples should be selected with consideration of culm age structure as well as culm size distribution in the stand for precise stand transpiration estimates. Thus, clarifying the effects of culm age on the individual culm transpiration rate is necessary for robust transpiration estimates based on sap flux for bamboo stands where culm age structures vary inter-annually.

The objective of this study is 1) to examine the potential effects of age structure changes on interannual variations in stand-scale transpiration, and 2) to examine whether or not samples should be selected with the consideration of culm age structure for stand-scale transpiration estimates, as the first step in obtaining robust transpiration estimates of bamboo stands. We conducted sap flux measurements for a total of 15 individuals that were classified into four age classes in a managed Moso bamboo forest in Kyoto, Japan. Then, we compared the sap flux density and individual culm transpiration among the four age classes.

\section{METHODS}

\section{Site characterization}

Sap flux measurements were conducted in a Moso bamboo (P. pubescens) forest at Kameoka City, Kyoto Prefecture, Japan $\left(34.99^{\circ} \mathrm{N}, 135.61^{\circ} \mathrm{E}, 150 \mathrm{~m}\right.$ a.s.l.) from August 29 to October 31,2014 . Annual mean air temperature of $14.6^{\circ} \mathrm{C}$ and annual mean precipitation of $1452 \mathrm{~mm}$ were recorded between 2003 and 2012 at the nearest meteorological observatory in Kameoka, $5 \mathrm{~km}$ from the study site. The 1.0 ha bamboo forest of the study site has been producing shoots for over five decades. This forest has clay soil and has been managed as follows: rapeseed meal fertilization (18.0 ton $\mathrm{ha}^{-1} \mathrm{yr}^{-1}$ ), thinning of older culms (older culms develop a yellow color and have fewer leaves), removal of bamboo shoot heads before some bamboo shoots have completely sprouted to keep the vegetation height low, and covering soil surface with a soil dressing annually to efficiently locate new early stage bamboo shoots (Ueda, 1963).

Air temperature, relative humidity (RSW-20S, ESPEC MIC Corp., Aichi, Japan) and rainfall (K5606QG, Yokogawa Denshikiki Co., Ltd., Tokyo, Japan) measurements were conducted at an open area in the study site every 10 minutes.
Mean volumetric soil water content at the depth of $0-30 \mathrm{~cm}$ was measured at the study plot at 30 minute intervals using a data logger (CR1000, Campbell Scientific Inc., Logan, UT, USA) with three $30-\mathrm{cm}$ long time domain reflectometers (CS650, Campbell Scientific Inc.). Solar radiation (CMP11, Kipp \& Zonen, Delft, The Netherlands) was recorded on average every $30 \mathrm{~min}$ on the flat roof of a building at Kyoto University, $25 \mathrm{~km}$ from the study site.

\section{Stand structure measurements}

The $100 \mathrm{~m}^{2}(10 \times 10 \mathrm{~m})$ plot was established in a flat area of the study site. The mean bamboo height, mean culm DBH and the bamboo density of the plot were approximately $7.1 \mathrm{~m}, 7.5 \mathrm{~cm}$ and 6800 culms ha $^{-1}$, respectively. Mean leaf area index of $3.7 \mathrm{~m}^{2} \mathrm{~m}^{-2}$ was measured using a plant canopy analyzer (LAI-2000, Li-Cor Inc., Lincoln, NE, USA) at the plot on December 9, 2014. To identify culm age, bamboo shoots grown in 2014 (1 yr) and 2013 (2 yr) were marked with paint on the culm surfaces. Excluding the bamboo culms that appeared in 2013 and 2014, the age of bamboo culms appearing before 2012 were separated into younger $(>$ $3 \mathrm{yr} y)$ or older ( $>3 \mathrm{yr}$ o) classes based on the white wax line at the bamboo nodes. In this study, bamboo culms with and without white wax lines on the node were categorized as belonging to the younger and older age classes, respectively, because the white wax line disappears based on culm age (Shinohara et al., 2013).

\section{Sap flux measurements}

Sap flux density per unit cross sectional area of culm $\left(F_{\mathrm{d}}\right.$; $\mathrm{cm}^{3} \mathrm{~m}^{-2} \mathrm{~s}^{-1}$ ) was measured using the thermal dissipation method with Granier-type sensors (Granier, 1987). The pair of probes was inserted into the stem, about $15 \mathrm{~cm}$ apart, in a vertical direction. Constant heat was supplied to the upper probe, while the lower probe recorded the stem temperature. The heat was dissipated into the xylem, and gave an estimate of the vertical sap flux surrounding the probes. For bamboo, we used 10-mm long and 2-mm diameter probes with a $0.15 \mathrm{~W}$ constant power supply to the upper probes based on Kume et al. (2010a) and Ichihashi et al. (2015). A sensor was inserted into each culm at breast height (approximately $1.3 \mathrm{~m}$ ). All sensors were installed facing north on the culms and were fully insulated to avoid solar radiation and penetration by rain water. The temperature differences were scanned every $30 \mathrm{~s}$ and recorded on average every $30 \mathrm{~min}$ using a data logger (CR1000) with a peripheral multiplexer(AM16/32, Campbell Scientific Inc.). The temperature difference was converted to $F_{\mathrm{d}}$ as described by Granier (1987) with a modified empirical constant proposed by Onozawa et al. (2009) and Kume et al. (2010a). Mean air temperature, vapor pressure deficit $(V P D)$, and volumetric soil water content during the study period were $17.4^{\circ} \mathrm{C}, 0.51 \mathrm{kPa}$ and $0.27 \mathrm{~m}^{3} \mathrm{~m}^{-3}$, respectively.

Individual culm transpiration $\left(Q_{\mathrm{t}} ; \mathrm{cm}^{3} \mathrm{~s}^{-1}\right)$ was calculated from multiplying the $F_{\mathrm{d}}$ by the cross sectional area of culm $\left(A_{\mathrm{S} \mathrm{b}} ; \mathrm{cm}^{2}\right)$. For $A_{\mathrm{S} \mathrm{b}}$ estimates, the culm thickness was measured for all sample bamboo by drilling a $2.5 \mathrm{~mm}$ diameter hole at breast height prior to the sap flow measurements, and the measurements were taken as the mean of two orthogonal measurements. $A_{\mathrm{S} \text { b }}$ was calculated from the $\mathrm{DBH}$ and the culm thickness. We assumed that the culm cross-sections were circular. 
Table I. Data summary of samples used for sap flux measurement

\begin{tabular}{lccc}
\hline Culm age class & Mean $\mathrm{DBH}^{*}(\mathrm{~cm})$ & Mean tree height $(\mathrm{m})$ & Mean culm sectional area $\left(\mathrm{cm}^{2}\right)$ \\
\hline 1 yr $(n=4)^{* *}$ & $8.7(1.1)^{* * *}$ & $7.1(1.9)$ & $23.2(4.7)$ \\
2 yr $(n=4)$ & $8.2(1.4)$ & $7.5(1.6)$ & $20.3(4.9)$ \\
$>3$ yr_y $(n=4)$ & $8.9(1.8)$ & $8.3(1.0)$ & $24.0(6.9)$ \\
$>3$ yr_o $(n=3)$ & $8.4(1.4)$ & $7.4(2.1)$ & $22.0(5.1)$ \\
\hline
\end{tabular}

* Diameter at breast height; ** Number of bamboo for sap flux measurement; *** A numeral in the parenthesis indicates the standard deviation.

To characterize the response of daily mean $F_{\mathrm{d}}$ to daily mean $V P D$, the exponential saturation was used (e.g., Ewers et al., 2008):

$$
F_{\mathrm{d}}=a\left(1-\mathrm{e}^{-b V P D}\right)
$$

where $a$ is the saturation parameter and $b$ is the curvature (response) parameter. Nonlinear fits were performed using the Levenberg-Marquardt method (Fujita et al., 1994) in KaleidaGraph (version 4.1.1, Synergy Software, Reading, PA, USA). The differences in the curvature parameter $b$ among four age classes were tested with one-way analysis of variances.

The period mean daily $F_{\mathrm{d}}$ and $Q_{\mathrm{t}}$ were obtained by the following procedures. 30-min data of $F_{\mathrm{d}}$ and $Q_{\mathrm{t}}$ were first averaged and summed during 24 hours, respectively. The daily data was then averaged over the study period.

We selected three to four bamboos from each culm age class for sap flux measurement. Four samples of bamboos were selected from each culm age class of $1 \mathrm{yr}, 2 \mathrm{yr}$, and $>3 \mathrm{yr} y$, and three samples of bamboos were selected from culm age class of $>3$ yr_o (Table I). Samples of bamboos were evenly selected across various DBH ranges in each age class.

\section{RESULTS}

\section{Stand structure}

DBH ranged from $5.1 \mathrm{~cm}$ to $11.3 \mathrm{~cm}$ (mean $7.5 \mathrm{~cm}$; mode $8.6 \mathrm{~cm}$; Figure 1a). Numbers of culms for $2 \mathrm{yr}(n=25)$ were largest in the four age classes, and were comparable with those for $>3 \mathrm{yr} \_\mathrm{y}(n=20)$ and $>3 \mathrm{yr} \_\mathrm{o}(n=17)$. Numbers of culms for $1 \mathrm{yr}(n=6)$ were the smallest in the four age classes (Figure 1a).

Mean DBH was not significantly different among four age classes (Figure $1 \mathrm{~b} ; p=0.26$ ). Culm thickness ranged from 0.8 to $1.1 \mathrm{~cm}$ (mean $0.9 \mathrm{~cm}$ ), which was moderately related to $\mathrm{DBH}(R=0.68, p<0.001)$. Basal area and total crosssectional area of culm walls were 31.1 and $12.6 \mathrm{~m}^{2} \mathrm{ha}^{-1}$, respectively.

\section{Diurnal and day-to-day variations in sap flux}

Figure 2 shows the diurnal courses of mean $F_{\mathrm{d}}$ for three or four individuals for each of four age classes, $R_{\mathrm{s}}$, and VPD on given days without rain. The peaks of the diurnal patterns of $F_{\mathrm{d}}$ occurred at noon, and the peaks of the $F_{\mathrm{d}}$ have considerable variations within and among age classes. In the cross-correlation analysis, the diurnal variations in mean $F_{\mathrm{d}}$ for each age class showed maximum correlation with $V P D$ (a)

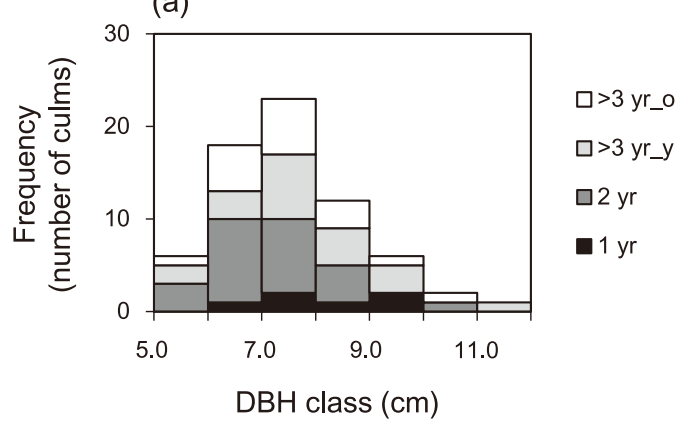

(b)

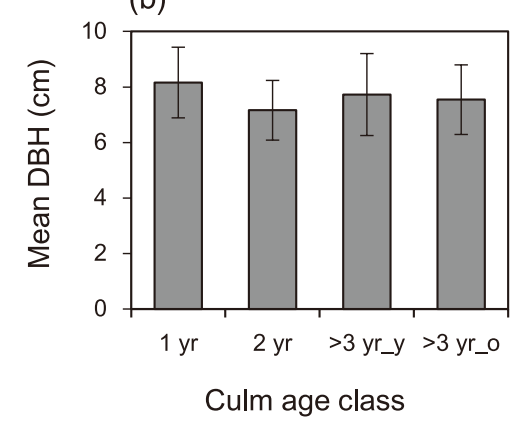

Figure 1. (a) Frequency distributions of stem diameter at breast height $(\mathrm{DBH})$ with respect to each culm age class; 1 year old ( $1 \mathrm{yr}), 2$ years old $(2 \mathrm{yr})$, more than 3 years with relatively younger $\left(>3 \mathrm{yr} \_\mathrm{y}\right)$, and older $\left(>3 \mathrm{yr} \_\right.$o) culms, (b) Mean DBH and standard deviation among the four culm age classes analyzed here

after a time lag of $1.0 \mathrm{~h}(R=0.84-0.85)$ and with $R_{\mathrm{s}}$ after a time lag of $0.5-1.0 \mathrm{~h}(R=0.83-0.85)$. No clear differences in the time lag among four age classes were observed.

Figure 3 shows the relationship between daily mean VPD and daily mean $F_{\mathrm{d}}$ of each individual for the four age classes. The $F_{\mathrm{d}}$ was correlated to $V P D$ for all individuals $(R=0.60$ $0.84)$. The differences in the responses of $F_{\mathrm{d}}$ to $V P D$ among the four age classes were not significant (Supplement Table SII; $p=0.53)$. An apparent decline of $F_{\mathrm{d}}$ at the higher range of $V P D$ for older age classes was not observed.

\section{Effects of culm age on relationship between DBH and individual culm transpiration}

Period mean daily $F_{\mathrm{d}}$ measured at each individual ranged from 4.5 to $25.1 \mathrm{~cm}^{3} \mathrm{~m}^{-2} \mathrm{~s}^{-1}$ (Figure 4 ). $F_{\mathrm{d}}$ was weakly and 



Figure 2. Diurnal variations in (a) vapor pressure deficit (VPD; thick line), solar radiation $\left(R_{\mathrm{s}}\right.$; thin line) and sap flux density $\left(F_{\mathrm{d}}\right)$ of four different age classes; (b) 1 year old (1 yr), (c) 2 years old (2 yr), (d) more than 3 years with relatively younger age ( $\left.>3 \mathrm{yr} \_\mathrm{y}\right)$, and (e) more than 3 years with relatively older age ( $>3 \mathrm{yr} \_$o). The number of culms for sap flux measurements was also shown in (b)-(e). Vertical bars represent standard error

insignificantly related to DBH (Figure $4 \mathrm{~b} ; R=0.44, p<0.1$ ). No significant difference of $F_{\mathrm{d}}$ among four age classes was observed $(p=0.66)$.

Period mean daily $Q_{\mathrm{t}}$ measured at each individual ranged from 0.74 to $5.5 \mathrm{~kg} \mathrm{~d}^{-1}$. $Q_{\mathrm{t}}$ was correlated to $\mathrm{DBH}$ across four age class (Figure 4c; $R=0.74, p<0.001$ ) because of a strong positive correlation between $\mathrm{DBH}$ and $A_{\mathrm{S} \text { b }}$ (Figure $\left.4 \mathrm{a} ; A_{\mathrm{S} \mathrm{b}}=3.7503 \mathrm{DBH}-9.6601, R=0.98\right)$. The difference in period mean daily $Q_{\mathrm{t}}$ among four age classes was also not significant $(p=0.85)$.

\section{DISCUSSION AND CONCLUSIONS}

The lack of a renewal of vascular bundles may cause older culms to have a lower $F_{\mathrm{d}}$ because of the decline in hydraulic conductance of the soil-leaf pathway. Normally, the highest rates of water transport are mostly found in the youngest and

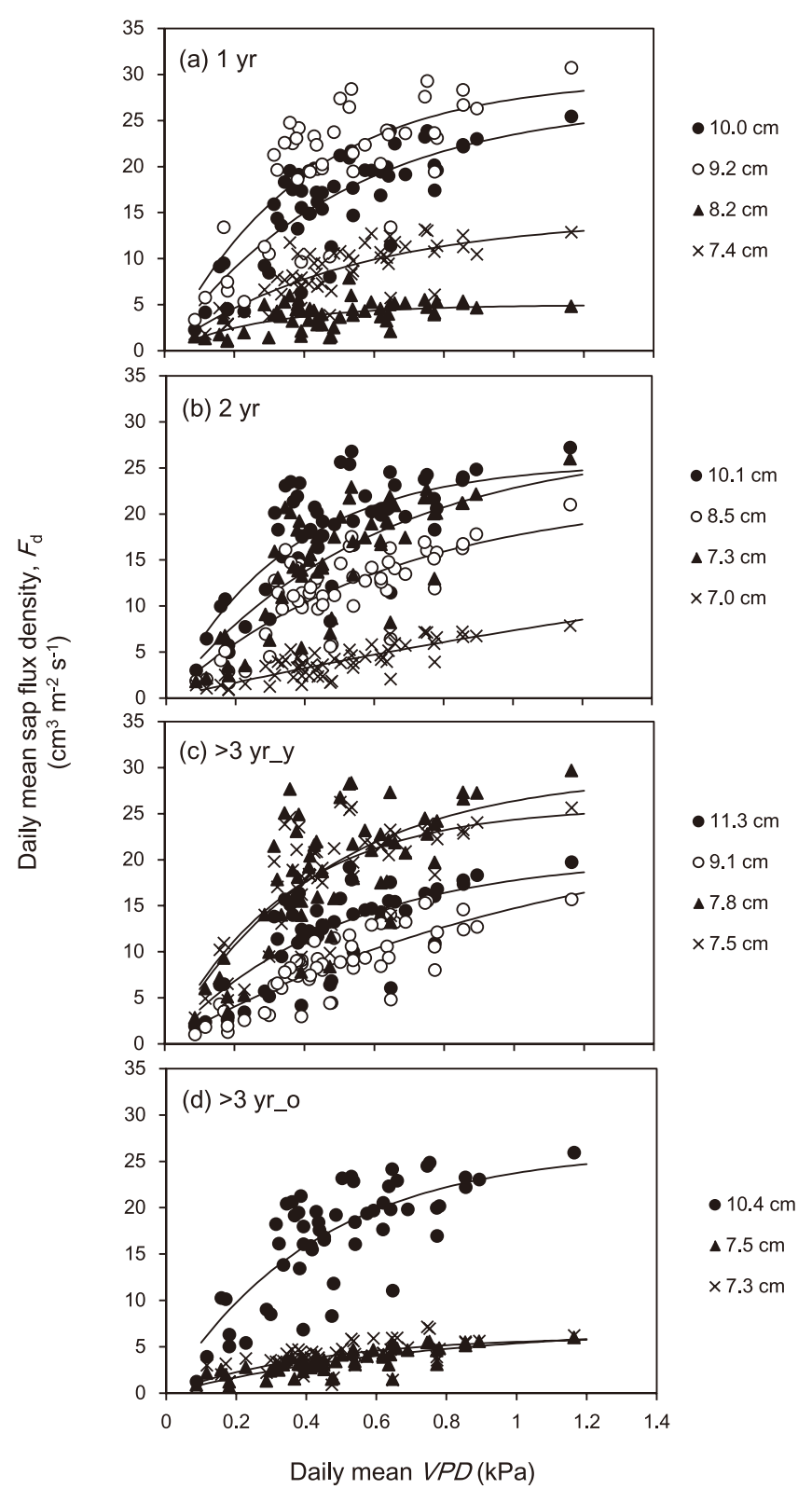

Figure 3. Relationship between daily mean vapor pressure deficit $(V P D)$ and daily mean sap flux density $\left(F_{\mathrm{d}}\right)$ for four different aged culm classes; (a) 1 year old (1 yr), (b) 2 years old $(2 \mathrm{yr})$, (c) more than 3 years with relatively younger $(>$ $\left.3 \mathrm{yr} \_\mathrm{y}\right)$, and (d) older ( $>3 \mathrm{yr} \_$o) culms. Numeral of each legend indicates diameter at breast height. Parameters of the curve fits are listed in Supplement Table SI

outermost vessels in tree species (e.g., Tateishi et al., 2008; Tsuruta et al., 2010; Umebayashi et al., 2010; Kume et al., 2012). On the other hand, in this study, $F_{\mathrm{d}}$ and its response to $V P D$ did not show apparent differences among culm age classes (Figure 3 and $4 \mathrm{~b}$ ). Also, time lags between $V P D, R_{\mathrm{s}}$, and $F_{\mathrm{d}}$ among the culm age classes did not show clear differences, and were comparable with a previous study (Kume et al., 2010a). Variations in $Q_{\mathrm{t}}$ were almost explained by variations in DBH (Figure 4c). These results suggest that culm age may not affect $F_{\mathrm{d}}$ and $Q_{\mathrm{t}}$ in the Moso bamboo forest. 
(a)
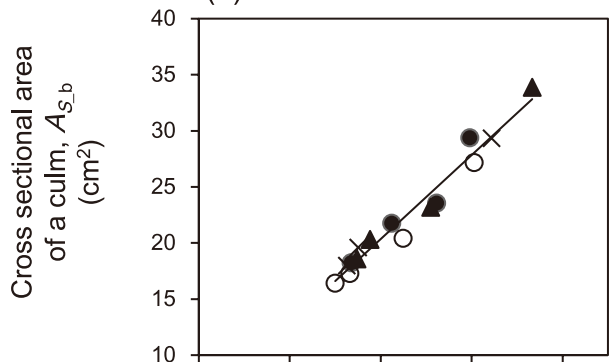

(b)



(c)
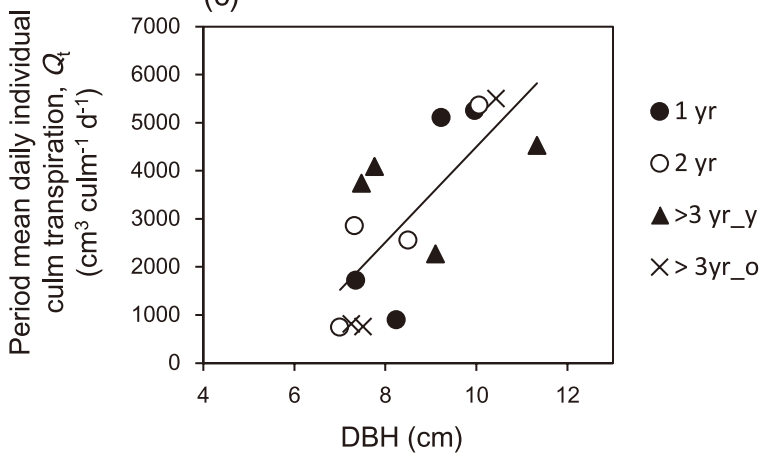

Figure 4. Relationship between diameter at breast height (DBH) and (a) cross sectional area of a culm $\left(A_{\mathrm{S} \text { b }}\right)$, (b) sap flux density $\left(F_{\mathrm{d}}\right)$, and (c) whole-bamboo transpiration $\left(Q_{\mathrm{t}}\right)$ for four different aged culm classes; 1 year old (1 yr), 2 years old $(2 \mathrm{yr})$, more than 3 years with relatively younger (>3 yr_y), and older (>3 yr_o) ages. Black lines in (a) and (c) represent regression equations derived across the four aged culm classes $\left(A_{\mathrm{S} \mathrm{b}}=3.7503 \mathrm{DBH}-9.6601 ; R=0.98, Q_{\mathrm{t}}\right.$ $=993.0 \mathrm{DBH}-5431 . \overline{4} ; R=0.74$, respectively)

Forest management practices at the study site may have an influence on our results. The study site is managed using local management practices (Ueda, 1963) including nearannual thinning of relatively old bamboo culms that turned yellow and had lost many leaves. It is still possible that much older bamboos than were analyzed in the present study may show a decline in $F_{\mathrm{d}}$ when compared with younger culms. Indeed, Moso bamboo culms sometimes live longer than 10 years (Isagi et al., 1997). Root pressure could be another possible reason for insignificant effects of culm age. Cao et al. (2012) reported high levels of root pressure in giant bamboo species, suggesting that hydraulic dysfunction in Moso bamboo might be moderated through the creation of root pressure caused by the refilling of cavitated conduits with a positive root pressure induced by sap.
Several studies have reported that $Q_{\mathrm{t}}$ was correlated with DBH for many tree species (e.g., Cermák et al., 2004; Tsuruta et al., 2008; Takagi, 2013) as found in this research (Figure 4). The daily amount of $Q_{\mathrm{t}}$ in a 90 -year-old Japanese cypress forest ranged from approximately 7.0 to $13.0 \mathrm{~kg} \mathrm{~d}^{-1}$ with DBH ranging from 25.0 to $35.0 \mathrm{~cm}$ (Takagi, 2013). Tsuruta et al. (2008) also reported the daily amount of $Q_{\mathrm{t}}$ in a 23-year-old Japanese cypress forest, showing that $Q_{\mathrm{t}}$ ranged from 4.1 to $9.0 \mathrm{~kg} \mathrm{~d}^{-1}$ with DBH ranging from 8.4 to $12.6 \mathrm{~cm}$. The daily amount of $Q_{\mathrm{t}}$ of bamboos for this study with DBH ranging from 7.0 to $11.3 \mathrm{~cm}$ (Figure 3c; 0.74$5.5 \mathrm{~kg} \mathrm{~d}^{-1}$ ) was comparable with that of the 23-year-old Japanese cypress forest.

Previous studies reporting larger stand-scale transpiration in Moso bamboo forests than that of the surrounding coniferous forests (Komatsu et al., 2010; Ichihashi et al., 2015) have not considered the effects of culm age on transpiration. This could lead to the following two problems. 1) Uncertainty of stand-scale transpiration estimates of Moso bamboo forests caused by a failure to consider variabilities in standscale transpiration; this variation is probably caused by significant interannual variations of age structure in Moso bamboo forests (Li et al., 1998), and 2) inaccurate sap fluxbased stand-scale transpiration estimates based on sampling without consideration of culm age structure (i.e., biased sampling). Our results suggest that interannual variations in stand-scale transpiration caused by culm age structure changes are small, in addition, samples can be selected without consideration of culm age structure for sap flux measurements at this site.

Ichihashi et al. (2015) reported that the mean stand $F_{\mathrm{d}}$ averaged over all sample culms in a dense unmanaged Moso bamboo forest was smaller than that of a recently thinned Moso bamboo forest in Fukuoka, Japan (Supplement Table SII). Canopy stand transpiration as the multiple of mean stand $F_{\mathrm{d}}$ and stand sapwood area was similar between the unmanaged and thinned Moso bamboo forests despite a much higher culm density in the unmanaged bamboo forest. The unmanaged bamboo forest probably has a higher proportion of older culms because no thinning had been conducted when compared with a managed bamboo forest. Therefore, it is still possible that old culms might have a low $F_{\mathrm{d}}$ in the unmanaged bamboo forest.

In addition, increased $Q_{\mathrm{t}}$ in the managed (thinned) bamboo forest compared with that of the unmanaged (un-thinned) forest at a given DBH might be another reason for the comparable stand-scale transpiration between the unmanaged and managed Moso bamboo forests. Previous studies in tree species reported increases of $F_{\mathrm{d}}$ after thinning that were probably caused by high sunlight exposure of individual crowns in a thinned forest (Morikawa et al., 1986; Sun et al., 2014).

We found almost the same $F_{\mathrm{d}}$ among the four age classes at the given DBH in the managed Moso Bamboo forest in Kyoto in the present study. This result contributes to robustness of random sampling for long-term sap flux-based standscale transpiration estimates. However, future studies will still need additional sap flux measurements on older culms in unmanaged bamboo forests with variations in culm density to accurately characterize stand-scale transpiration in Moso bamboo forests. 


\section{ACKNOWLEDGMENTS}

The authors are grateful to members of the Okumuras for their sincere help with our field observations at the bamboo site. We are also grateful to Dr. Mai Kamakura, Dr. Makiko Tateishi, Mr. Hiroyuki Yamamoto, and Mr. Jun Tsuruta (Kyoto University) for their assistance with stand structure and sap flow measurements and to Dr. Susumu Tohno (Kyoto University) for providing solar radiation data. We express sincere thanks to two anonymous reviewers for their critical comments. The National Science Council in Taiwan (Grant No. 103-2313-B-002-009-MY3), Sumitomo Foundation, the Japanese Ministry of Education, Culture, Sports, Science and Technology through a Grant-in-Aid for Scientific Research (\#25 2764), and Research Institute for Sustainable Humanosphere, Kyoto University supported this research.

\section{SUPPLEMENTS}

Table SI. Parameters for the relationship between daily mean sap flux density $\left(F_{\mathrm{d}}\right)$ and daily mean vapor pressure deficit $(V P D)$ for each bamboo (Equation (1); Figure 3)

Table SII. Comparison of sap flux measurements in Moso bamboo stands

\section{REFERENCES}

Cao KF, Yang SJ, Zhang YJ, Brodribb TJ. 2012. The maximum height of grasses is determined by roots. Ecology Letters 15: 666-672. DOI: 10.1111/j.1461-0248.2012.01783.x.

Čermák J, Cienciala E, Kučera J, Lindroth A, Bednářová E. 1995. Individual variation of sap-flow rate in large pine and spruce trees and stand transpiration: a pilot study at the central NOPEX site. Journal of Hydrology 168: 17-27. DOI: 10.1016/0022-1694(94)02657-W.

Čermák J, Kučera J, Nadezhdina N. 2004. Sap flow measurements with some thermodynamic methods, flow integration within trees and scaling up from sample trees to entire forest stands. Trees 18: 529-546. DOI: 10.1007/s00468-004-0339-6.

Chiou CR, Chen TH, Lin YJ, Yang YJ, Li SD. 2009. Distribution and change analysis of bamboo forest in northern Taiwan. Quarterly Journal of Chinese Forestry 42: 89-105 (in Mandarin with English summary).

Dierick D, Hölscher D, Schwendenmann L. 2010. Water use characteristics of a bamboo species (Bambusa blumeana) in the Philippines. Agricultural and Forest Meteorology 150: 15681578. DOI: 10.1016/j.agrformet.2010.08.006.

Ewers BE, Mackay DS, Tang J, Bolstad PV, Samanta S. 2008. Intercomparison of sugar maple (Acer saccharum Marsh.) stand transpiration response to environmental conditions from the Western Great Lakes Region of the United States. Agricultural and Forest Meteorology 148: 231-246. DOI: 10.1016/j.agrformet.2007.08.003.

Fujita H, Konno H, Tanabe K. 1994. Optimization method. Applied mathematics, Iwanami Shoten Publishers, Tokyo, Japan; 170 (in Japanese).

Granier A. 1987. Evaluation of transpiration in a Douglas-fir stand by means of sap flow measurements. Tree Physiology 3: 309320. DOI: 10.1093/treephys/3.4.309.
Gratani L, Crescente MF, Varone L, Fabrini G, Digiulio E. 2008. Growth pattern and photosynthetic activity of different bamboo species growing in the Botanical Garden of Rome. Flora 203: 77-84. DOI: 10.1016/j.flora.2007.11.002.

Ichihashi R, Komatsu H, Kume T, Onozawa Y, Shinohara Y, Tsuruta K, Otsuki K. 2015. Stand-scale transpiration of two Moso bamboo stands with different culm densities. Ecohydrology 8 : 450-459. DOI: 10.1002/eco.1515.

Imaji A, Ueda M, Waguchi Y, Tanaka M, Uematsu A, Kasuya N, Ikeda T. 2013. Effects of bamboo colonization on water relations of Japanese cedar (Cryptomeria japonica) and Hinoki cypress (Chamaecyparis obtusa). Journal of Japanese Forestry Society 95: 141-146. DOI: 10.4005/jjfs.95.141 (in Japanese with English summary).

Isagi Y, Kawahara T, Kamo K, Ito H. 1997. Net production and carbon cycling in a bamboo Phyllostachys pubescens stand. Plant Ecology 130: 41-52. DOI: 10.1023/A:1009711814070.

Komatsu H, Onozawa Y, Kume T, Tsuruta K, Kumagai T, Shinohara Y, Otsuki K. 2010. Stand-scale transpiration estimates in a Moso bamboo forest: (II) comparison with coniferous forests. Forest Ecology and Management 260: 1295-1302. DOI: 10.1016/j.foreco.2010.06.040.

Komatsu H, Onozawa Y, Kume T, Tsuruta K, Shinohara Y, Otsuki K. 2012. Canopy conductance for a Moso bamboo (Phyllostachys pubescens) forest in western Japan. Agricultural and Forest Meteorology 156: 111-120. DOI: 10.1016/j.agrformet.2012.01.004.

Kume T, Onozawa Y, Komatsu H, Tsuruta K, Shinohara Y, Umebayashi T, Otsuki K. 2010a. Stand-scale transpiration estimates in a Moso bamboo forest: (I) applicability of sap flux measurements. Forest Ecology and Management 260: 1287-1294. DOI: 10.1016/j.foreco.2010.07.012.

Kume T, Tsuruta K, Komatsu H, Kumagai T, Higashi N, Shinohara Y, Otsuki K. 2010b. Effects of sample size on sap flux-based stand-scale transpiration estimates. Tree Physiology 30: 129138. DOI: 10.1093/treephys/tpp074.

Kume T, Otsuki K, Du S, Yamanaka N, Wang YL, Liu GB. 2012. Spatial variation in sap flow velocity in semiarid region trees: its impact on stand-scale transpiration estimates. Hydrological Processes 26: 1161-1168. DOI: 10.1002/hyp.8205.

Li R, Werger MJA, During HJ, Zhong ZC. 1998. Carbon and nutrient dynamics in relation to growth rhythm in the giant bamboo Phyllostachys pubescens. Plant and Soil 201: 113-123. DOI: 10.1023/A:1004322812651.

Meinzer FC, Goldstein G, Jackson P, Holbrook NM, Gutierrez MV, Cavelier J. 1995. Environmental and physiological regulation of transpiration in tropical forest gap species: the influence of boundary layer and hydraulic conductance properties. Oecologia 101: 514-522. DOI: 10.1007/BF00329432.

Morikawa Y, Hattori S, Kiyono Y. 1986. Transpiration of a 31-yearold Chamaecyparis obtusa Endle. stand before and after thinning. Tree Physiology 2: 105-114. DOI: 10.1093/treephys/ 2.1-2-3.105.

Oishi AC, Oren R, Novick KA, Palmroth S, Katul GG. 2010. Interannual invariability of forest evapotranspiration and its consequence to water flow downstream. Ecosystems 13: 421436. DOI: $10.1007 / \mathrm{s} 10021-010-9328-3$.

Onozawa Y, Kume T, Komatsu H, Tsuruta K, Otsuki K. 2009. Applicability of sap flux measurements in Moso bamboo (Phyllostachys pubescens): relationship between water absorption and whole-tree water use utilizing Granier sensor sap flux measurements. Journal of Japanese Forestry Society 
91: 366-370. DOI: 10.4005/jjfs.91.366 (in Japanese with English summary).

Shinohara Y, Komatsu H, Kuramoto K, Otsuki K. 2013. Characteristics of canopy interception loss in Moso bamboo forests of Japan. Hydrological Processes 27: 2041-2047. DOI: 10.1002/hyp.9359.

Shinohara Y, Kume T, Ichihashi R, Komatsu H, Otsuki K. 2014. Moso-bamboo forests in Japan: what are the effects of their area expansion on ecosystem services? Journal of Japanese Forestry Society 96: 351-361. DOI: 10.4005/jjfs.96.351 (in Japanese with English summary).

Song X, Zhou G, Jiang H, Yu S, Fu J, Li W, Wang W, Ma Z, Peng C. 2011. Carbon sequestration by Chinese bamboo forests and their ecological benefits: assessment of potential, problems, and future challenges. Environmental Reviews 19: 418428. DOI: 10.1139/a11-015.

Sperry JS. 1993. Winter embolism and spring recovery in Betula cordifolia, Fagus grandifolia, Abies balsamifera, and Picea rubens. In Water Transport in Plants Under Climatic Stress, Borghetti M, Grace J, Raschi A (eds). Cambridge University Press: Cambridge, UK; 86-98.

Sun X, Onda Y, Otsuki K, Kato H, Hirata A, Gomi T. 2014. The effect of strip thinning on tree transpiration in a Japanese cypress (Chamaecyparis obtusa Endl.) plantation. Agricultural and Forest Meteorology 197: 123-135. DOI: 10.1016/j. agrformet.2014.06.011.

Takagi M. 2013. Evapotranspiration and deep percolation of a small catchment with a mature Japanese cypress plantation. Journal of Forest Research 18: 73-81. DOI: 10.1007/s10310011-0321-2.

Tateishi M, Kumagai T, Utsumi Y, Umebayashi T, Shiiba Y, Inoue
K, Kaji K, Cho K, Otsuki K. 2008. Spatial variations in xylem sap flux density in evergreen oak trees with radial-porous wood: comparisons with anatomical observations. Trees 22: 23-30. DOI: 10.1007/s00468-007-0165-8.

Tsuruta K, Kume T, Komatsu H, Higashi N, Kumagai T, Otsuki K. 2008. Relationship between tree height and transpiration for individual Japanese cypress (Chamaecyparis obtusa). Journal of Japan Society of Hydrology and Water Resources 21: 414-422. DOI: 10.3178/jjshwr.21.414 (in Japanese with English summary).

Tsuruta K, Kume T, Komatsu H, Higashi N, Umebayashi T, Kumagai T, Otsuki K. 2010. Azimuthal variations of sap flux density within Japanese cypress xylem trunks and their effects on tree transpiration estimates. Journal of Forest Research 15: 398-403. DOI: 10.1007/s10310-010-0202-0.

Ueda K. 1963. Useful bamboos and the shoots: a new technique of cultivation. Hakuyu-sha, Tokyo, Japan; 314 (in Japanese).

Umebayashi T, Utsumi Y, Koga S, Inoue S, Matsumura J, Oda K, Fujikawa S, Arakawa K, Otsuki K. 2010. Xylem waterconducting patterns of 34 broadleaved evergreen trees in southern Japan. Trees 24: 571-583. DOI: 10.1007/s00468010-0428-7.

Wang F, Tian X, Ding Y, Wan X, Tyree MT. 2011. A survey of root pressure in 53 Asian species of bamboo. Annals of Forest Science 68: 783-791. DOI: 10.1007/s13595-011-0075-1.

Wilson KB, Hason PJ, Mulholland PJ, Baldocchi DD, Wullschleger SD. 2001. A comparison of methods for determining forest evapotranspiration and its components: sap-flow, soil water budget, eddy covariance and catchment water balance. Agricultural and Forest Meteorology 106: 153-168. DOI: 10.1016/S0168-1923(00)00199-4. 